\title{
Novas diretrizes em tempos desafiadores: formação em Psicologia para atuar na Educação
}

\author{
Anabela Almeida Costa e Santos Peretta \\ Universidade Federal de Uberlândia - Uberlândia - MG \\ Silvia Maria Cintra da Silva \\ Universidade Federal de Uberlândia - Uberlândia - MG \\ Flaviana Franco Naves \\ Universidade Federal de Uberlândia - Uberlândia - MG \\ Fabiana Marques Barbosa Nasciutti \\ Universidade Estadual de Campinas - Campinas - SP \\ Larice Santos Silva \\ Universidade Federal de Uberlândia - Uberlândia - MG
}

\begin{abstract}
Resumo
As Diretrizes Curriculares Nacionais para os Cursos de Psicologia de 2004 implicaram em uma reorganização curricular em ênfases e núcleos comuns. O objetivo desta pesquisa foi analisar a formação dada aos futuros psicólogos quanto à ênfase em processos educativos, tendo em vista as Diretrizes. Participaram da pesquisa cinco instituições mineiras, sendo duas universidades públicas e três privadas. Foram obtidas informações por meio de: análise dos projetos curriculares; entrevistas com coordenadores de curso e professores; questionários respondidos por estudantes dos $4^{\circ \mathrm{s}}$ e $5^{\circ \mathrm{s}}$ anos. Constatamos que as ênfases em processos educativos têm adotado direções promissoras em termos de prepararem os futuros psicólogos para se relacionar com o campo da Educação e desenvolver práticas que colaborem para a construção de processos educativos emancipatórios. Contudo, em Minas Gerais poucos cursos de Psicologia oferecem ênfases relacionadas aos processos educativos. Destaca-se, portanto, a relevância de que o psicólogo seja legalmente reconhecido como profissional da educação.
\end{abstract}

Palavras-chave: Formação do psicólogo; currículo; psicologia escolar.

\section{New Guidelines in Times of Challenge: Psychology education to act in the educational field}

\begin{abstract}
The 2004 National Curriculum Guidelines for courses in Psychology was followed by the reorganization of curriculum into emphases. The aim of this research is to analyze the formation available to future psychologists with respect to the educational processes emphasis in the light of those guidelines. Five institutions from Minas Gerais has participated in the survey: two public universities and three private ones. Information was obtained through: survey and analysis of curricular projects; interviews with course coordinators and professors; and questionnaires answered by students from 4th and 5th years. It has been noticed that the emphasis in educational processes has adopted a promising direction in terms of preparing future psychologists to be related with the field of Education and developed practices that collaborate in the construction of emancipatory educational processes. However, in Minas Gerais, few Psychology courses offer emphases related to educational processes. It stands out, therefore, the relevance of a legally recognized psychologist as a professional of education.
\end{abstract}

Keywords: Psychologists education; curriculum; school psychology.

\section{Nuevas directrices en tiempos desafiadores: formación en Psicología para actuar en la Educación}

\section{Resumen}

Las Directrices Curriculares Nacionales para los Cursos de Psicología de 2004 implicaron en una reorganización curricular en énfasis y núcleos comunes. El objetivo de esta investigación fue analizar la formación dada a los futuros psicólogos cuanto al énfasis en procesos educativos, teniendo en vista las Directrices. Participaron de la investigación cinco instituciones mineras, siendo dos universidades públicas y tres privadas. Se obtuvieron informaciones por medio de: análisis de los proyectos curriculares; entrevistas con coordinadores de curso y profesores; cuestionarios respondidos por estudiantes de los $4^{\text {os }}$ y $5^{\circ s}$ años. Se constató que los énfasis en procesos educativos han adoptado direcciones promisoras en términos de preparara los futuros psicólogos para relacionarse con el campo de la Educación y desarrollar prácticas que colaboren para la construcción de procesos educativos emancipador. Sin embargo, en Minas Gerais pocos cursos de Psicología ofrecen énfasis relacionados a los procesos educativos. Se destaca, por lo tanto, la relevancia de que el psicólogo sea legalmente reconocido como profesional de la educación. Palabras clave: formación del psicólogo; curriculum; psicología escolar. 


\section{Introdução}

A Psicologia como ciência e profissão passou por importantes transformações nas últimas décadas. De uma profissão marcadamente comprometida e voltada para as elites, passamos a ter atualmente uma ampliação das áreas e camadas da população atendidas. Como aponta Furtado (2012), ainda que não tenha havido uma mudança radical no perfil do psicólogo, ocorreu uma evolução no perfil da profissão que tem superado seu caráter liberal, tradicionalmente alocado em consultórios particulares, passando agora a ocupar múltiplos locais de atuação.

A formação do psicólogo tem uma estreita relação com essas alterações. Relação que se dá tanto ao disparar mudanças no modo como a Psicologia se relaciona com a sociedade e se reconhece como profissão, quanto ao responder à ampliação dos campos de atuação e aos enfrentamentos com os quais tem se deparado. Mello(1980) analisou os cursos de Psicologia em seus primórdios e verificou que optaram por um modelo de formação centrado em uma concepção clínica e de profissional liberal. As disciplinas presentes no currículo enfatizavam a formação nas áreas de psicodiagnóstico, avaliação psicológica e psicoterapias. Esse quadro se manteve nos anos 1960 e 1970. Conforme analisa Mello (1980), a partir de meados da década de 1980, os currículos dos cursos de Psicologia passam a ser alvo de críticas pelo fato de excluírem vários aspectos da realidade social do país e por ensinarem uma psicologia dita neutra e científica, com bases claramente positivistas e a-históricas. O trabalho do psicólogo escolar e educacional exemplificava bem este momento, ao basear-se quase exclusivamente na aplicação de testes psicológicos para determinar o Q.I. ou a deficiência de crianças em idade escolar, definindo o encaminhamento para classes especiais.

Também é neste momento que as relações entre a Psicologia e o campo da educação começam a passar por transformações importantes. O trabalho de Maria Helena Souza Patto (1984) - denunciando os compromissos ideológicos assumidos pela Psicologia, que justificava o fracasso escolar com base em problemas centrados nos alunos e/ou em suas famílias, colaborando para escamotear processos históricos, sociais e políticos - desencadeou discussões, pesquisas e o desenvolvimento de novos referenciais teórico-práticos para a Psicologia Escolar e Educacional e para a ciência psicológica de modo mais amplo.

Tais críticas foram profícuas e contribuíram para a construção de outros modos de pensar e fazer a Psicologia Escolar e Educacional, com bases teórico-metodológicas comprometidas com a educação de qualidade e o desenvolvimento humano. Como apontam Maluf e Cruces (2008):

Agora é tempo de mostrar como pode a Psicologia Educacional estar a serviço do bem-estar da comunidade escolar, do desenvolvimento psicológico de todos os envolvidos no processo educacional, da aprendizagem significativa que produzirá no aluno as condições individuais e sociais necessárias para o pleno exercício da cidadania(pp. 95-96).
Na década de 1990 temos a aprovação da Lei de Diretrizes e Bases da Educação Nacional, exigindo transformações profundas no modo como se organizava o ensino superior no país e desencadeando o amplo processo de discussão, descrito por Hoff (1999), sobre como deveria ocorrer a formação em Psicologia, culminando nas Diretrizes Curriculares Nacionais (DCN), publicadas em 2004 (Brasil, 2004).

As DCN propõem a substituição dos antigos currículos mínimos por uma nova organização dos cursos, agora baseada em núcleos comuns e ênfases. Em ambas as etapas, competências e habilidades que devem ser conquistadas. As DCN estabelecem que as ênfases não devam ser estruturadas como especializações em práticas, procedimentos ou locais de atuação do psicólogo. Configuram-se, portanto, de modo bastante diferente da anterior separação nas tradicionais áreas da Psicologia (Clínica, Escolar e Organizacional). O documento destaca, como um dos exemplos de ênfase que pode ser adotada, a ênfase em Psicologia e processos educativos, que é a que nos interessa mais diretamente.

Com o intuito de compreender melhor este momento de transformação na formação em Psicologia, voltando especial atenção à formação para atuação no campo da educação, desenvolvemos o estudo descrito neste artigo. O objetivo geral desta pesquisa foi analisar a formação dada aos futuros psicólogos nos Cursos de Graduação em Psicologia quanto à ênfase nos processos educativos, tendo em vista as novas Diretrizes Curriculares Nacionais vigentes. Nossos objetivos específicos configuram-se em: a) conhecer o que dizem os documentos oficiais produzidos pelos cursos de formação, sobretudo no que se refere à dimensão educativa do trabalho do psicólogo (disciplinas, ementas, propostas de estágio curricular, projetos de extensão universitária); b) investigar quais princípios e concepções compõem o pensamento e a prática universitária de professores e coordenadores de curso no que se refere à formação/atuação do psicólogo; c) compreender como o discurso teórico da área de Psicologia Escolar e Educacional comparece nos documentos oficiais dos cursos de formação em Psicologia e no pensamento e na prática docente universitária, priorizando a ênfase em processos educativos.

\section{Percurso Metodológico}

A pesquisa aqui apresentada compõe o estudo multicêntrico intitulado "A formação do psicólogo escolar e as Diretrizes Curriculares em Psicologia: concepções teóricas, bases metodológicas e atuação profissional”. Este estudo contou com a participação de pesquisadores dos estados de São Paulo, Goiás, Rondônia e Minas Gerais ${ }^{1}$, que utilizaram

1 A pesquisa teve a coordenação geral da Profa. Dra. Marilene Proença Rebello de Souza, responsável também pelo estado de São Paulo. Nos demais estados, a coordenação ficou a cargo das seguintes docentes: Profa. Dra. Gisele Toassa (Goiás), Profa. Dra. Tania Suely Azevedo Brasileiro (Rondônia) e Profa. Dra. Silvia Maria Cintra da Silva e Profa. Dra. Anabela Almeida Costa e Santos Peretta (Minas Gerais). 
procedimentos metodológicos semelhantes. Foi considerado que tais estados representam diferentes realidades brasileiras e que assim os resultados da pesquisa podem contribuir para ampliar a compreensão das questões da formação/ prática profissional em Psicologia no campo da educação

Trataremos neste artigo das informações obtidas em Minas Gerais, estado que tem tido significativa participação no cenário nacional de formação de psicólogos, contando com 58 cursos de graduação em Psicologia².Participaram da pesquisa cinco das principais instituições formadoras mineiras, sendo duas universidades públicas e três privadas, cujos cursos de Psicologia eram oferecidos há mais de 10 anos. Foram escolhidas Instituições de Ensino Superior (IES) que apresentassem experiência consolidada nas áreas de ensino, pesquisa e extensão e que tivessem adotado ênfases relacionadas aos processos educativos ${ }^{3}$, atendendo aos objetivos propostos pela investigação.

A pesquisa, de caráter quantitativo e qualitativo, envolveu duas fases de construção de informações, a saber: a) documental, por meio do levantamento e análise dos documentos oficiais que norteiam a formação junto às instituições de ensino superior delimitadas neste estudo; b) empírica, por meio de instrumentos como a entrevista, realizada com coordenadores de curso e professores e questionário, respondido por estudantes dos $4^{\text {os }}$ e $5^{\circ s}$ anos de Psicologia das IES selecionadas.

Em relação à documentação oficial, foram levantadas informações, por meio do Cadastro da Educação Superior ${ }^{4}$, de documentos e arquivos fornecidos pelos coordenadores e nos sites das IES. Foi realizada cuidadosa leitura desses documentos, buscando-se reunir e organizar informações relativas à caracterização dos cursos. Mais especificamente em relação aos projetos pedagógicos, pretendia-se verificar como as proposições contidas nas DCN compareciam nos documentos oficiais, priorizando elementos relativos à dimensão educativa do trabalho do psicólogo.

Foram realizadas entrevistas audiogravadas com 13 professores, cinco coordenadores de curso e um ex-coordenador $^{5}$, as quais versaram sobre as DCN para os cursos de

\footnotetext{
2 Segundo o site: http://emec.mec.gov.br/, consultado no período de junho de 2011 a junho de 2012.

3 Encontramos diferentes nomenclaturas para as ênfases. Optamos por não mencioná-las para preservar a identidade das IES participantes da pesquisa. Adotaremos a nomenclatura genérica ênfase em processos educativos para os cinco cursos.

4 Conforme informa o site do MEC (https://emec.mec.gov.br/), "o Cadastro da Educação Superior (Cadastro e-MEC) é uma ferramenta que permite ao público a consulta de dados sobre instituições de educação superior e seus cursos. Em relação às instituições de ensino, é possível pesquisar informações sobre as universidades, centros universitários e faculdades vinculadas ao sistema federal de ensino, que abrange as instituições públicas federais e todas as instituições privadas de ensino superior do país. O Cadastro informa dados como a situação de regulação das instituições e dos cursos por elas oferecidos, endereços de oferta e indicadores de qualidade obtidos nas avaliações do MEC".

5 Em uma das IES, o coordenador atual ocupava o cargo havia pouco tempo e, por isso, sugeriu que conversássemos também com o ex-coordenador que havia acompanhado todo o processo de formulação do projeto pedagógico sob as DCN. Assim, optamos por entrevistar ambos.
}

graduação em Psicologia e o seu processo de implantação. Buscamos conhecer as alterações produzidas nos currículos em decorrência da mudança da legislação e também foram feitas perguntas em relação à ênfase em processos educativos. Os professores entrevistados trabalhavam diretamente com os componentes curriculares desta ênfase e, portanto, foi junto a eles que obtivemos mais elementos em relação ao processo de formação profissional para atuar no campo da educação.

A fim de conhecer a compreensão dos discentes sobre a supracitada temática, aplicamos 197 questionários compostos por questões abertas e fechadas, referentes ao perfil sociocultural e a como os alunos avaliavam e compreendiam a própria formação, destacando aspectos referentes à ênfase em processos educativos.

Partimos do pressuposto de que a realidade social é subjetiva, múltipla, dinâmica, resultado de uma construção dos sujeitos participantes, mediante a interação com outros membros da sociedade e, portanto, adotamos métodos de investigação diversos que pudessem contemplaras diferentes dimensões que compõem o fenômeno que nos propusemos a esmiuçar. Spink (1999) propõe a triangulação metodológica, ou seja, a utilização de técnicas múltiplas para que se conheça o objeto de pesquisa proposto. Utilizamos a triangulação de informações quantitativas e qualitativas, mas também de pessoas, métodos e instrumentos, a fim de enriquecer o estudo a respeito de um fenômeno complexo e multifacetado como o processo de formação profissional.

O questionário forneceu informações quantitativas e qualitativas. Em relação às questões abertas realizamos a categorização das informações e a análise de conteúdo das respostas obtidas. Para análise dos dados quantitativos da amostra foi adotado o pacote estatístico Statistical Package for the Social Sciences - SPSS - versão 20.0. Quanto às entrevistas, foram transcritas e analisadas utilizando procedimentos de análise de conteúdo, tal como é definida por Bardin (2000), ou seja, as comunicações foram analisadas por meio de procedimentos sistemáticos e objetivos de descrição do conteúdo das falas. A compreensão das entrevistas visou à exploração do material de modo a organizá-lo, possibilitando que fossem feitas interpretações e inferências.

Para Rockwell (1987), o processo de interpretação refere-se à compreensão do significado das ações e do que é dito, com determinadas especificidades e dificuldades que Ihe são inerentes: "interpretar requer compartilhar, dentro do possível, 'o conhecimento local'; compreender o que é dito como o fazem os outros sujeitos da localidade implicaria, dentre outras coisas, compartilhar toda a sua experiência comum, o que é impossível" (p. 27). Mesmo que a partilha absoluta de significados seja impossível, é importante que o pesquisador procure essa aproximação. Neste sentido, ressaltamos que o conhecimento gradual acerca da situação estudada, assim como de seus participantes e o cotejamento de respostas por estes fornecidas podem ser recursos relevantes (Rockwell, 1987).

Porém, além dessa aproximação com as categorias "locais", com o modo como os indivíduos vivem a situação 
estudada, é necessário construir categorias analíticas que permitam estabelecer relações e conceitualizações que escapem àqueles que estão imersos numa determinada realidade. Para isso, as pesquisadoras se debruçaram sobre as transcrições das entrevistas em busca de regularidades e padrões, a fim de realizar uma codificação e categorização que possibilitasse a articulação entre os avanços teóricos da Psicologia Escolar e Educacional e as práticas adotadas no âmbito da formação do profissional para atuar no campo da educação.

Para este artigo, propusemos a apresentação da triangulação das informações construídas por meio de documentos, entrevistas e questionários visando a realizar uma síntese dos resultados gerais obtidos pela supracitada pesquisa no estado de Minas Gerais. O conjunto dos dados foi organizado nas seguintes temáticas: a) A implementação das DCN na formação profissional de psicólogos; b) O que dizem documentos, alunos e a equipe pedagógica sobre a formação de psicólogos? c) Efetivação da proposta de formação profissional de psicólogos frente aos processos educativos.

\section{Resultados e Discussão}

Iniciaremos esta seção com uma breve apresentação das cinco IES participantes da pesquisa. Três cursos existem há mais de 35 anos e dois há cerca de 15 anos. Aqueles se constituíram muito antes das Diretrizes Curriculares de 2014 e, com o advento destas, precisaram debruçar-se sobre o documento para efetuar as reformulações necessárias; estes, mais jovens em relação a tais discussões, puderam reorganizar-se de outras formas, pois nenhuma turma havia se formado em 2004. Em relação ao número de vagas oferecidas, temos 70 a 120 vagas anuais; quanto ao período de funcionamento, dois são noturnos, dois integrais (um com um período noturno) e um matutino. A seguir detalharemos as temáticas elaboradas a partir da triangulação dos dados.

\section{Aimplementação das DCN na formação profissional de psicólogos}

As DCN desencadearam mudanças profundas na maioria dos cursos pesquisados. Os projetos pedagógicos foram reformulados, imprimindo significativas transformações em relação às pretensões relativas ao perfil do egresso. Este processo se revelou em diferenças no cotidiano universitário e na estruturação das atividades curriculares e extracurriculares.

De fato, as DCN propõem alterações significativas no modo de organização dos cursos, mas não foram proposições que surgiram repentinamente. Desde o final da década de 1990 as discussões a respeito de como deveria ser composto este documento envolveram diversos profissionais e entidades de classe (Hoff, 1999; Yamamoto, 2000). Esta história de construção das Diretrizes marca o nascimento de um dos cursos participantes da pesquisa. Trata-se da IES3 ${ }^{6}$ cujo curso de Psicologia foi criado pouco antes da instituição das DCN. Assim, a aprovação das Novas Diretrizes não teve grande impacto no cotidiano institucional e os professores relatam que ao formularem o projeto pedagógico já incorporaram diversos aspectos que vinham sendo discutidos, tais como o estágio básico e a formação para a pesquisa.

Os docentes e os coordenadores de todas as universidades visitadas consideram que as DCN são um avanço importante na trajetória de formação do psicólogo e destacam como principais pontos positivos: a) a possibilidade de que os cursos criem ênfases amplas quanto à área de conhecimento e atuação; b) a proposta de fortalecimento da articulação entre teoria e prática; c) e o fato de abarcarem demandas contemporâneas, voltadas para aspectos sociais. Os pontos destacados são coerentes com as proposições das DCN e estão presentes em todos os projetos pedagógicos analisados.

Ainda que considerem que as Diretrizes representam um avanço no que se refere à qualidade da formação em Psicologia, não deixaram de apontar aspectos negativos relativos aos interesses subjacentes à elaboração do documento, ao modo de implantação das ênfases e à organização dos cursos em torno da aquisição de competências e habilidades. São pontos importantes, cuja discussão pode contribuir para que as DCN sejam implementadas de modo comprometido com a qualidade da formação.

O primeiro ponto refere-se à história de construção das DCN, processo descrito por Yamamoto (2000) como um "espaço de conflito". Os professores também fizeram referência a isso manifestando contrariedade em relação ao fato de as DCN apresentarem proposta claramente vinculada aos interesses teórico-metodológicos dos grupos que as elaboraram. Hoff (1999) relata o amplo processo de discussão que ocorreu em torno da elaboração das DCN. Sendo a Psicologia uma área do conhecimento composta por diversas matrizes teóricas e concepções a respeito dos fenômenos psicológicos, é compreensível que a formulação de diretrizes para a formação resulte num documento atravessado por tais divergências.

Outro importante aspecto ressaltado por coordenadores e professores foi a preocupação com a possibilidade de que as ênfases acabem por tornar-se especializações. Referem-se a um descompasso na articulação entre o núcleo comum e as ênfases, revelando que os cursos não estão conseguindo propor uma organização curricular que possibilite apropriação suficiente dos diversos campos da Psicologia. Assim, em geral, os alunos não têm a possibilidade de circular pelos diversos campos da Psicologia e cursar pelo menos duas ênfases, seja pelos custos financeiros implicados ou pela carga horária que prolongaria excessivamente a formação. Tal fenômeno contraria o que é proposto no parágrafo $1^{\circ}$ do artigo 12 das Diretrizes: "o subconjunto

6 A partir deste ponto, diferenciaremos as IES participantes da pesquisa utilizando a numeração de 1 a 5 . Também utilizaremos números para diferenciar os professores que nos concederam entrevistas. 
de competências definido como escopo de cada ênfase deverá sersuficientemente abrangente para não configurar uma especialização em uma prática, procedimento ou local de atuação do psicólogo" (Brasil, 2004, p.4).

No entanto, como destaca Souza (2010), para conhecer as políticas públicas é necessário ir além dos documentos, pois é no dia-a-dia e nas relações das instituições educativas, num espaço conflituoso, esperançoso e utópico que se materializam as legislações. Nas palavras de um professor:

Eu acho que a Diretriz abre possibilidade pra isso [para formar um profissional ético e preparado tecnicamente], mas eu acho que vai depender muito. Porque eu tenho um projeto pedagógico que pode ser bem legal, mas quem dá vida a ele é o corpo docente em interação com os alunos (IES3 Prof.1).

O uso dos conceitos competências e habilidades também foi alvo de críticas. Os professores apontam que são conceitos restritivos, que contribuem para a fragmentação da formação e ressaltam que há elementos relevantes para a formação do psicólogo que não são contemplados nessa concepção de formação. Conforme analisa Ramos (2001), o conceito de competências, largamente utilizado nas políticas educacionais atuais, reduz o sentido do conhecimento ao pragmatismo. E, assim, a validade dos saberes seria julgada por sua viabilidade ou por sua utilidade. Moraes também critica tal conceito, contextualizando a discussão sob a perspectiva da educação vista como mercadoria, sendo-lhe "atribuída a função de formar a força de trabalho com as 'competências' necessárias para atender ao mercado" (2001, p. 9).

Ainda em relação ao modo como foram implantadas as DCN, professores e coordenadores ressaltam que a organização em ênfases permitiu uma flexibilidade maior quanto às possibilidades de atuação. Outra mudança significativa foi que os cursos passaram a abarcar projetos sociais e ações de prevenção e promoção de saúde, deixando de ter um enfoque meramente clínico-tradicional. Além disso, foi incorporado o ensino de teorias mais contemporâneas, visando oferecer uma formação pluralista, generalista e humanizada. Tais elementos comparecem nos projetos pedagógicos dos cinco cursos pesquisados.

Em síntese, as DCN instauraram a necessidade de profundas modificações no modo como vinha se dando a formação de psicólogos. São mudanças que estão sendo testadas e reformuladas, num contínuo processo. A implantação das ênfases surge como um fenômeno paradoxal. Por um lado é um dispositivo que possibilita que a formação se volte para campos de atuação mais amplos do que era concebido pelas tradicionais áreas de atuação da Psicologia; por outro lado, no modo como têm sido implantadas, as ênfases acabam por implicar em que os alunos façam escolhas precoces e tenham que optar ainda em sua graduação por um direcionamento em relação ao campo de atuação da Psicologia ao qual pretendem dedicar-se.

\section{O que dizem documentos, alunos e a equipe pedagógica sobre a formação de psicólogos?}

No contexto da implantação das $\mathrm{DCN}$, buscamos compreender quais eram os princípios e concepções que compõem o pensamento e a prática docente universitária no que se refere à formação/atuação do psicólogo. Nesta seção, abordaremos algumas das concepções que fundamentam a formação em psicologia oferecida nas IES pesquisadas.

Em relação à concepção de homem, encontramos, tanto nas declarações de professores e coordenadores como nos projetos pedagógicos, uma visão crítica, ou seja, a realidade histórica, cultural e social em que os indivíduos estão inseridos é considerada tanto para se compreendero sujeito como para o desenvolvimento de práticas profissionais:

Quando você não contextualiza, quando você não entende que o homem, que o psiquismo, ele não é feito dissociado do contexto (...) o fenômeno é visto de uma forma alienada. (...) Então o profissional que é alienado que não consegue ver, ele vai ver o fenômeno de uma forma alienada (IES5 Prof. 2)

Como destaca Bock (2009), é fundamental que a Psicologia busque "construir leituras que, ao falarem do mundo psíquico, falem do mundo social e, ao pensarem em transformações, psíquicas, exijam um projeto social" (p. 23). Compreender um sujeito localizado/situado é um dos elementos que contribui para a construção de uma psicologia crítica que seja comprometida com a solução de problemas postos pelas práticas e relações sociais. Contribui, deste modo, para a superação de uma Psicologia considerada ciência pura, que esteja aparentemente desconectada das necessidades reais que se apresentam aos sujeitos e, logo, de uma psicologia neutra.

A relação entre teoria e prática foi um dos temas explorados. Nos projetos pedagógicos está presente a indissociabilidade entre teoria e prática e todos os entrevistados referem-se à importância de que a formação em Psicologia abranja tanto aspectos teóricos quanto práticos. Alguns professores revelam preocupação de que haja coerência neste sentido:

Tem alguns que eu percebo (...) que têm um discurso bacaninha, mas quando você vai conhecer um pouco da prática, aí você fala: "nossa, mas onde que estava aquilo que ele estava falando?". Então, tem uma dissonância no discurso. E eu acho que esse é um desafio que a gente tem. De ter uma coerência entre um discurso e a ação (IES5 Prof.1).

Tal desafio lembrado pelo docente nos remete a um aspecto, citado por apenas um dos professores, mas que destacamos por sua relevância extrema quando se trata da formação profissional: a questão da práxis. Segundo Vásquez (2007): 
A práxis se apresenta como uma atividade material, transformadora... Fora dela fica a atividade teórica que não se materializa, na medida em que é atividade espiritual pura. Mas, por outro lado, não há práxis como atividade puramente material (...). Isto significa que o problema de determinar o que é a práxis requer delimitar mais profundamente as relações entre teoria e prática (p. 237).

A teoria é um recurso necessário para que a Psicologia seja marcada pela perspectiva crítica e pelo compromisso social, caso contrário toda prática ficaria esvaziada de sentido. Ainda citando Vásquez (2007), "toda práxis é atividade, mas nem toda atividade é práxis" (p. 219). Neste sentido ressalta-se a importância da práxis como elemento que compareça na formação em Psicologia, buscando uma atuação comprometida com um projeto político para a transformação social.

Num sentido oposto ao da práxis, é preocupante o modo como alguns professores referiram-se às teorias ensinadas. Disseram utilizar diferentes referenciais teóricos para os diversos contextos de atuação, ou seja, acabam por adotar um ecletismo. Entendendo a prática profissional como ação humana intencionada, alerta-se aqui para o cuidado de ocorrer uma cisão entre teoria e prática, entre teoria e pesquisador/psicólogo partindo para uma lógica que compreende uma teoria tecnicista, ou seja, para diferentes contextos ou atividades a serem realizadas utilizam-se diferentes teorias. Concordamos com as proposições de Saviani (2007) sobre teoria e prática, dimensões intrinsecamente relacionadas e que não podem ser colocadas em polos opostos, sob o risco de passarem a ser, respectivamente verbalismo (teoria sem prática) e ativismo (prática sem teoria). Para que possamos construir de modo crescente uma formação consistente, a questão da práxis surge como imprescindível.

A concepção de atuação do psicólogo manifestada por professores e coordenadores, também presente nos projetos pedagógicos, distancia-se da Psicologia tradicional. Diversos elementos encontrados indicam isto. A necessidade de que o psicólogo seja um profissional crítico e esteja preparado para trabalhar frente a diferentes realidades foi destacada, enfatizando que deve prevalecer o respeito à pluralidade e à diversidade. Os professores também se referem à importância de que os futuros psicólogos estejam preparados para trabalhar com temáticas como: violência contra a mulher, união homoafetiva, preconceito, xenofobia, racismo, alcoolismo, redução da maioridade penal. Esta concepção está em convergência com o atual movimento de expansão dos serviços do psicólogo para camadas mais amplas da população, como escreve Yamamoto (2007)

(...) ao longo destes quarenta anos de consolidação da profissão, o elitismo que marcou os primeiros tempos vem sendo paulatinamente contestado por um movimento, ainda tendencial e ainda longe de reverter o quadro da profissão, mas crescente, de expansão dos serviços do psicólogo para camadas mais amplas da população (p.33).
A preparação para atuar em redes e de modo interdisciplinar também compareceu como um dos elementos fundamentais da formação, tanto nas falas do corpo docente quanto nos projetos pedagógicos. No entanto, os alunos apontam como uma das competências menos desenvolvidas na graduação "Atuar inter e multiprofissionalmente sempre que a compreensão dos processos e fenômenos envolvidos assim o recomendar". Esta dissonância pode revelar que apesar do empenho do corpo docente, talvez ainda seja necessário dedicar mais esforços no sentido de garantir uma formação para este aspecto. A necessidade de que o psicólogo esteja preparado para atuar junto às políticas públicas aparece nos projetos pedagógicos, mas foi citada por apenas um dos professores e vale ser lembrada, dada a sua relevância.

Diante desta proposta de formação apresentada pelos projetos dos cursos e pela equipe pedagógica, uma certa contradição nos chamou a atenção. Nos questionários, os estudantes responderam que as competências gerais que estão sendo desenvolvidas mais intensamente são a realização de diagnóstico e avaliação dos processos psicológicos de indivíduos, de grupos e de organizações, ou seja, ações mais relacionadas a uma Psicologia tradicional. Estas respostas vão de encontro às demais informações que obtivemos. Podemos arriscar uma hipótese para compreender este fato. Nossa pesquisa optou por ouvir apenas os professores diretamente ligados à ênfase em processos educativos. Sabemos que, diante da diversidade de correntes e concepções que constituem a Psicologia como área de atuação e conhecimento, a Psicologia Escolar e Educacional tem tido um papel de vanguarda no sentido de discutir o papel individualizador e justificador de questões históricas e sociais. É possível que os princípios defendidos pelos docentes do campo da educação não representem a totalidade do curso. Corroborando esta explicação, apresentamos a seguinte declaração de um dos professores:

A dificuldade que eu vejo na ênfase de educação aqui, é que o nosso curso forma muito o modelo clínico ainda. Na minha concepção, tradicional. E aí na educação ele [o psicólogo]tem que ter essa escuta clínica, eu acho que ela está presente em qualquer um, mas ele tem que ter um olhar diferenciado, não dá pra pensar um psicólogo que vai trabalhar com essa parte da educação e com foco no atendimento individual (IES3 Prof.1).

\section{Efetivação da proposta de formação profissional de psicólogos frente aos processos educativos}

As DCN propõem as ênfases visando uma compreensão para além da clássica divisão por áreas de atuação, considerando um entendimento processual e ampliado do fazer psicológico. Nesta seção abordaremos aspectos relativos à visão de educação e ao modo como está se dando a implementação da ênfase em processos educativos. Des- 
tacamos que serão mais evidenciados posicionamentos dos docentes, dado que foi sobretudo com eles que pudemos aprofundar o diálogo sobre essa temática.

Em relação à concepção de Educação, predomina entre os professores uma concepção ampliada do fenômeno educativo, ou seja, a educação não está localizada somente em instituições como escola e família, mas diluída em todos os âmbitos sociais:

a primeira coisa que eu rompo com eles [os alunos] é pensar que processo educativo é sinônimo de escola, eu acho que o aluno tem que ter uma abertura pra todos os campos onde possa ter uma prática educativa, não está restrito à escola, eu tenho trabalhado muito com eles isso (IES3 Prof.1).

Se tomarmos o modo como a Educação aparece nas Diretrizes, veremos algo que se aproxima desta concepção apresentada pelos professores, dado que o documento propõe que as ênfases não devam ser configuradas por uma especialização em um local de atuação do psicólogo e que a ênfase em processos educativos deva voltar-se para o processo de educação e de ensino-aprendizagem em distintos contextos institucionais nos quais tais necessidades sejam detectadas.

Alguns afirmam que a educação tem grande potencial para produzir transformações na sociedade e mencionam a necessidade de que seja mais valorizada em termos políticos, econômicos e sociais. Os coordenadores não apresentaram tal concepção ampliada de educação. Contudo, é importante ressaltar que nenhum dos coordenadores tinha formação e/ ou atuação na área de Psicologia Escolar e Educacional.

Todos os professores consideram que a ênfase em processos educativos é importante para a formação do psicólogo. No entanto, aparecem diferenças em relação ao modo com expressam esta importância. Alguns professores compreendem que a ênfase contribui apenas para todos aqueles que pretendem atuar na área de Psicologia Escolar e Educacional. Outros professores acreditam numa contribuição que ultrapassa os limites de áreas de atuação, já que a dimensão educativa é constitutiva do ser humano e ao mesmo tempo da sociedade. Consideramos que esta dimensão é fundamental para a formação em Psicologia qualquer que seja suaárea de atuação.

Entre os docentes, predominam posicionamentos convergentes com a Psicologia Escolar crítica, no que se refere aos modos como a Psicologia pode atuar e contribuir com a Educação. A maioria dos professores afirma que a Psicologia Escolar não deve se basear no atendimento clínico e individualizante das questões escolares e, sim, privilegiar intervenções institucionais. O trabalho multidisciplinar é destacado como imprescindível para a atuação do psicólogo junto à educação. E para que haja efetivamente uma atuação multidisciplinar, é necessário que exista uma relação respeitosa com a equipe escolar, que supere uma visão preconceituosa dos professores e a culpabilização do docente e da gestão da escola pelos problemas da educação.
As concepções que embasam a formação defendida pelos professores estão em consonância com o que vem sendo proposto pela Psicologia Escolar Crítica, que defende, tal como apontam Asbahr, Martins e Mazzolini (2011):

uma formação em psicologia que possibilite intervenções apoiadas na compreensão dos inúmeros elementos que constituem a subjetividade em sua relação com a educação; ou seja, é necessário que o psicólogo compreenda como são organizadas as relações escolares, a dinâmica institucional da escola e os preconceitos engendrados no cotidiano escolar (p. 166-167).

Os professores, de modo geral, buscam oferecer aos seus alunos uma diversidade de experiências na área da educação, apresentando uma grande variedade nas temáticas abordadas: formação docente, formação do professor prático-reflexivo, afetividade, dificuldades de aprendizagem, relação família-escola, homossexualidade, educação sexual na escola, representação social da escola, adolescência em conflito coma lei, brincadeira. Preocupam-se também em oferecer práticas aos alunos que abranjam não apenas crianças, mas também adolescentes e adultos (professores e famílias).

Os professores comentam a necessidade de reconhecimento, pelo campo da Educação, das mudanças que ocorreram na Psicologia Escolar e Educacional:

Eu acho que o pessoal da Pedagogia não se dá conta plenamente em que lugar está a Psicologia hoje, eu acho que no interior da Pedagogia ainda se coloca a Psicologia num lugar em que ela não está mais, que é esse lugar dos enfoques cognitivos com tendência classificatória, com obsessão medicamentosa, eu acho que não é mais esse lugar. Acho que a Psicologia soma nessa maneira de pensar a Pedagogia e uma educação mais social mesmo, mais plural, da diferença, da pluralidade (IES3 Prof.4).

Assim, a Psicologia Escolar e Educacional deve ter como um de seus grandes objetivos contribuir para que haja mudanças na educação, no sentido de construir espaços mais propícios ao desenvolvimento humano, combatendo a medicalização, a rotulação e auxiliando para que sejam superados os preconceitos vigentes na escola. Para isto, é fundamental que o psicólogo que atua na educação conheça as políticas públicas.

Os professores destacam que o psicólogo escolar deve ter uma forte interlocução com os saberes e as práticas da educação, respeito à diversidade e preparo para lidar com as adversidades, aprender a dialogar com a escola, encontrando formas de superar as dificuldades que surgem para propor e desenvolver trabalhos. Os docentes fazem referência explícita à importância de que o psicólogo seja um profissional presente nas escolas, bem como que sejam ampliados os campos de atuação, devendo esta ser uma luta constante da Psicologia. 


\section{Considerações finais}

A partir da análise dos documentos, questionários e entrevistas que compuseram a pesquisa, é possível considerar que a formação em Psicologia está em processo de transformação. Caminha numa direção mais comprometida socialmente, atenta às necessidades da população $e$ menos centrada na clínica tradicional. A formação em processos educativos tem sido conduzida por profissionais que demonstram ter concepções afinadas com as discussões atuais da Psicologia Escolar e Educacional, comprometendo-se com a qualidade da educação e o desenvolvimento de todos os envolvidos no processo educativo. Isto pode indicar que as ênfases em processos educativos têm adotado uma direção promissora em termos de preparar os futuros psicólogos para estabelecer relações profícuas com o campo da Educação e para desenvolver práticas que colaborem para a construção de processos educativos emancipatórios.

Consideramos imprescindível que se amplie a compreensão sobre a dimensão educativa da formação em Psicologia, algo que contribuirá de modo muito significativo para que, de fato, a Psicologia esteja a serviço da construção de uma sociedade que possa possibilitar o desenvolvimento humano.

Contudo, diante de um crescimento no número de cursos de Psicologia, identificamos no estado de Minas Gerais um número reduzido de cursos de Psicologia que oferecem ênfases relacionadas aos processos educativos. Tal fato que havia sido estudado por Cruces (2009), que realizou pesquisa em 187 cursos de Psicologia disponíveis na página da Associação Brasileira de Ensino de Psicologia - ABEP e concluiu que das 60 instituições que informaram as ênfases escolhidas, somente 22 instituições a oferecem na área escolar ou educacional. Diversos autores referem-se também ao pequeno interesse dos alunos de graduação em Psicologia pela realização de estágios relacionados à Educação (Cruces, 2006; Guzzo, Costa, \& Santıanna, 2009).

Tal redução da participação da dimensão educativa nos cursos de Psicologia é deveras preocupante, tanto pela lacuna em termos de formação, quanto pelo fato de que num futuro próximo teremos poucos profissionais preparados para responder às demandas e especificidades da Educação. No entanto, a opção de diversas IES por não priorizar a Educação em suas ênfases é compreensível frente ao inexpressivo campo de trabalho para o psicólogo no Estado de Minas Gerais, apesar de as queixas escolares ainda configurarem a grande demanda encaminhada a serviços públicos e consultórios particulares (Silva, \& cols., 2012) ${ }^{7}$. Frente a essa situação, destaca-se a relevância de que o psicólogo possa ser legalmente reconhecido como um profissional da educação, que pode colaborar efetivamente com os processos educativos ${ }^{8}$.

7 Silva e cols. (2012) realizaram um mapeamento em 47 cidades do estado de Minas Gerais, buscando informações sobre os psicólogos que atendessem às demandas escolares. Em apenas 21 cidades havia psicólogos contratados pelas Secretarias de Educação.

8 O Projeto de Lei 3688/2000, que prevê a inserção de profissionais
Ainda no que se refere à formação de psicólogos, é imprescindivel que os projetos pedagógicos prevejam ênfases que possam, de fato, ser cursadas paralelamente, possibilitando uma formação mais ampla que garanta que os futuros profissionais estejam preparados para assumir os desafios contemporâneos colocados para a profissão.

A pesquisa aqui relatada não esgota a discussão sobre a legislação atual e a formação dos psicólogos, tema que merece mais estudos. Contudo, contribui com a importante reflexão a respeito desta formação, que precisa ser vista e compreendida como um processo contínuo e constante e que deve articular-se e estar afinada com a realidade objetiva e com as necessidades concretas da população, algo em constante transformação. Fica aqui o convite para que projetos pedagógicos, docentes e coordenadores incorporem ao cotidiano dos cursos a mudança como requisito necessário à formação e à atuação do psicólogo.

\section{Referências}

Asbahr, F. S. F., Martins, E., \& Mazzolini, B. P. M. (2011). Psicologia, formação de psicólogos e a escola: desafios contemporâneos. Psicologia em Estudo, 16(1), 157-163.

Bardin, L. (2000). Análise de conteúdo. Lisboa: Edições.

Bock, A. B. (2009). A Psicologia Sócio-Histórica: uma perspectiva crítica em Psicologia. Em A. B. Bock, M. D. Gonçalves, \& O. Furtado (Orgs.), Psicologia Sócio-Histórica: uma perspectiva crítica em Psicologia. São Paulo: Cortez.

Brasil. Ministério da Educação. Conselho Nacional de Educação. Câmara de Educação Superior (2004). Parecer 0062/2004, aprovado em 19/02/2004, fixa as Diretrizes Curriculares Nacionais para os cursos de graduação em Psicologia. Brasília.

Cruces, A. V. (2006). Psicologia e educação: nossa história e nossa realidade. Em S. F. C. Almeida (Org.), Psicologia Escolar: ética e competências na formação e atuação profissional (pp. 17-36). Campinas, SP: Alínea.

Cruces, A. V. (2009). Desafios e Perspectivas para a Psicologia Escolar com a implantação das Diretrizes Curriculares. Em C. M. Marinho-Araújo (Org.), Psicologia Escolar: novos cenários e contextos de pesquisa, formação e prática (pp. 15-34). Campinas, SP: Alínea.

Furtado, O. (2012). 50 anos de Psicologia no Brasil: a construção social de uma profissão. Psicologia: Ciência e Profissão, 32(Special Issue), 66-85. Recuperado: 24 jun. 2014. Disponível: http://www.

da Psicologia e do Serviço Social na rede pública de educação básica, tramita desde o ano 2000 e está atualmente aguardando Deliberação na Comissão de Constituição e Justiça e de Cidadania (CCJC), segundo informações obtidas em 10 de julho de 2014 no site http://www.camara.gov.br/proposicoesWeb/fichadetramitacao?i dProposicao $=20050$. 
scielo.br/scielo.php?script=sci arttext\&pid=\$1414989320120005 00006\&lng=en\&tlng=pt.10.1590/S1414-98932012000500006.

Guzzo, R. S., Costa, A. S., \& Sant'anna, I. M. (2009). Formando psicólogos escolares: problemas, vulnerabilidades, desafios e horizontes. EmC. M. Marinho-Araújo (Org.), Psicologia Escolar: novos cenários e contextos de pesquisa, formação e prática (pp. 35-52). Campinas, SP: Alínea.

Hoff, M. S. (1999). A proposta de Diretrizes Curriculares para os cursos de Psicologia: uma perspectiva de avanços? Psicologia Ciência e Profissão, 3(19), 19-31.

Maluf, M. R., \& Cruces, A. V. (2008). Psicologia Educacional na contemporaneidade. Boletim Academia Paulista de Psicologia, 28(1), 87-99.

Mello, S. L. (1980). Psicologia e Profissão em São Paulo. São Paulo: Ática.

Moraes, M. C. (2001) Recuo da teoria: dilemas na pesquisa em educação. Revista Portuguesa de Educação, 14(1), 7-25.

Patto, M. H. (1984). Psicologia e Ideologia: reflexões sobre psicologia escolar. São Paulo: T.A. Queiroz.

Ramos, M. N. (2001). A pedagogia das competências: autonomia ou adaptação? São Paulo: Cortez.

Rockwell, E. (1987). Reflexiones sobre el processo etnográfico. Ciudad de México: DIE/CINVESTAV.
Saviani, D. (2007). Pedagogia: o espaço da educação na universidade. Cadernos de Pesquisa, 37(130), 99-134.

Silva, S. M. C., Lima, C. P., Silva, A. C. O., Rezende, P. C. M., Carrijo, R. S., Ribeiro, M. J., Mazuchelli, D. S. R., \& Barreto, V. S. (2012) O psicólogo diante da demanda escolar: concepções e práticas no estado de Minas Gerais. Gerais: Revista Interinstitucional de Psicologia, 5, 36-49.

Souza, M. P. (2010). Psicologia Escolar e politicas públicas em educação: desafios contemporâneos. Em aberto, 23(83), 129-149.

Spink, M. J. (1999). Desvendando as teorias implícitas: uma metodologia de analise das representações sociais. Em P. A. Guareschi, \& S. Jovchelovitch (Orgs.), Textos em representações sociais. Petrópolis, RJ: Vozes.

Vásquez, A. S. (2007). Filosofia da Práxis. São Paulo: Expressão Popular.

Yamamoto, O. H. (2000). A LDB e a Psicologia. Psicologia: ciência e profissão, 20(4), 30-37.

Yamamoto, O. H. (2007). Políticas sociais, "terceiro setor" e "compromisso social": perspectivas e limites do trabalho do psicólogo. Psicologia \& Sociedade, 19(1). 


\section{Sobre as autoras}

Anabela Almeida Costa e Santos Peretta (anabelaacs@gmail.com)

Doutora em Psicologia Escolar e Desenvolvimento Humano, docente da Universidade Federal de Uberlândia.

Silvia Maria Cintra da Silva (silvia_ufu@hotmail.com)

Doutora em Educação, docente da Universidade Federal de Uberlândia.

Flaviana Franco Naves (flavinaves@yahoo.com)

Psicóloga, Mestre em Educação: Psicologia da Educação.

Fabiana Marques Barbosa Nasciutti (fabi.marquesb@hotmail.com)

Mestra em Psicologia, Doutoranda pela Faculdade de Educação da Unicamp.

Larice Santos Silva (laricesantos@yahoo.com.br)

Psicóloga, Mestranda pelo Instituto de Psicologia da Universidade Federal de Uberlândia.

Pesquisa financiada pela FAPEMIG - Processo No: APQ-00546-11 Demanda Universal 